\title{
Epistemology of Greek Harmonics
}

\author{
Danilo Capecchi \\ Dipartimento di ingegneria strutturale e geotecnica, University of Rome, Rome, Italy \\ Email: danilo.capecchi@uniroma1.it
}

Received 14 May 2015; accepted 27 June 2015; published 30 June 2015

Copyright (C) 2015 by author and Scientific Research Publishing Inc.

This work is licensed under the Creative Commons Attribution International License (CC BY).

http://creativecommons.org/licenses/by/4.0/

c) (†) Open Access

\begin{abstract}
Greek harmonics is the theory of the organization of notes with respect to the highness or lowness of their pitches. This was a mathematical science, a thorough knowledge of which was not necessary for the professional musician and was thus cultivated essentially by mathematicians and philosophers. For them, harmonics was mixed mathematics, the mix being between experimental assertions derived from hearing and propositions derived from reason, that was, mathematics. This classification was maintained through the Middle Ages and the Renaissance. Despite the important role played by harmonics in ancient science, little consideration has been given by historians of science. This study shows that harmonics merits a careful study and that its methods are the same as other sciences. Particular attention was devoted to Ptolemy who applied the same approach to harmonics as he did to astronomy, astrology and geography.
\end{abstract}

\section{Keywords}

Harmonics, Epistemology, History of Science, Greek Music, Mixed Mathematics

\section{Introduction}

The theory of organization of notes with respect to the highness or lowness of their pitches was named harmonics by the Greeks. Modern harmonics deals with concords, that is notes played simultaneously. Greek harmonics dealt with notes played in sequence or, in other words, musical scales. Even though the concept of concord was fundamental in it, to formulate a theory of a musical interval, Greek music was essentially melodic, with no use for concords (Comotti, 1991). Ptolemy and Aristoxenus, two of the most important theoreticians of the time, each provided a definition of harmonics. Ptolemy defined harmonics as a "perceptive function of the differences in sounds between high and low" (Ptolemy, 2000: p. 2). By extension, harmonics is the discipline that deals with the way in which sounds should be organized so that they sound "melodic", which is pleasurable to the ear.

Aristoxenus definition was more articulated:

Harmonics is only a part of the musician's accomplishment, as are the sciences of rhythm, metre and in- 
struments.

We must therefore give an account of harmonics and its parts. It is to be understood, speaking generally, as the science which deals with all melody, and enquires how the voice naturally places intervals as it is tensed and relaxed. For we assert that the voice has a natural way of moving, and does not place intervals haphazardly (Barker, 1989: p. 149).

Harmonics was a mathematical science, a thorough knowledge of which was not necessary for a professional musician and was thus cultivated essentially by mathematicians and philosophers. There were two main traditions, usually referred to as Pythagoreans and Aristoxenians. The former assumed that pitches of notes could be represented by integers and their relations by ratios (usually simple ratios). This was the dominant position of music theorists, namely Philolao, Archytas of Tarentun, Plato, Euclid, Theon, Nicomachus, and Ptolemy. The Aristoxenian school, on the other hand, denied the fundamentality of the mathematical representation of the pitches of sound and developed an essentially empirical approach, albeit quantitative and thus associated with mathematics.

Mathematicians and philosophers considered harmonics as a mixed mathematics (Renaissance terminology), the mix being between experimental assertions derived from hearing, and propositions derived from reason, or, rather, mathematics. This classification was maintained throughout the Middle Ages, where it was part of the quadrivium (arithmetic, geometry, music and astronomy), and the Renaissance (Palisca, 1985). In any scientific discussion of the 17th century, harmonics was involved. These discussions included, among others, René Descartes, Marin Mersenne, Johannes Kepler, Christiann Huygens, Athanasius Kirker, and John Wallis. Galileo Galilei considered several fundamental musical questions in his scientific writings and he was not only a lutanist himself, but also a son, brother, and father of musicians, in short, a member of a musical dynasty (Palisca, 1961: p. 92).

Despite the important role of harmonics in ancient science, little consideration has been given to this by historians of science. The great synthesis of the 20th century was carried out by Duhem, Koyré, Dijksterhuis, etc., practically ignores harmonics. This is not so for the historians of mathematics; most textbooks mention harmonics, because of the reference to the theory of proportions as well as the discussion on irrational numbers. Harmonics has been and is of course the object of historians of music that has written widely on the theme. Bibliographical references can be found in (Barker, 1989). However, they are not generally interested in science, apart from the fundamental works by Andrew Barker (Barker, 1978, 1989, 1994, 2006).

It is the purpose of the present paper to cover part of this gap, which to my opinion is inexcusable. In particular, the paper intends:

1) To clarify scientific aspects and the epistemological implication of various approaches;

2) To relate the epistemology of harmonics to that of other sciences.

A particular attention was devoted to conceptions of Ptolemy who used the same approach for harmonics as he did for astronomy, astrology, and geography.

\section{Fundaments of Greek Music}

According to a tradition going back to Aristotle, sounds were classified as discrete or continuous. Continuous sounds are such that no single part is equal-toned over a perceptible interval of time, that is there is a continuous variation in pitch. Discrete sounds are such that their parts remain equal-toned over a perceptible interval of time (Ptolemy, 2000: p. 15). Music and harmonics are concerned with discrete sounds only; a sound of a given pitch is called a note.

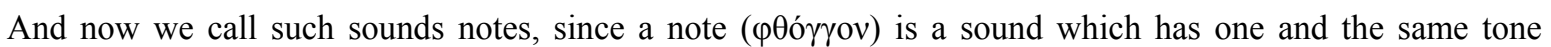
( óvos) (Ptolemy, 2000: p. 15).

But Greeks did not possess the concept of an absolute value for the pitch of a note; they only could say that one pitch was higher than another (today we know that pitches are associated with the frequencies of vibration of air, a physical magnitude measured in Hz-cycles per second. A note corresponds to a given frequency; for instance we associate $440 \mathrm{~Hz}$ with the note La). In a Greek context a note alone had no sense, it was "irrational" (Ptolemy, 2000: p. 15) ${ }^{1}$. A note thus should be associated with other different notes. Such associations are made up of emmelic (melodic) notes, which when joined together are acceptable to the ear; otherwise they are made

${ }^{1}$ Barker translates "has no ratio" (Barker, 1989: p. 284). But I prefer irrational, though the meaning probably refers in both cases to mathematics. 
up of ecmelic (unmelodic) notes. They are termed concordant if they create a homogeneous impression on the hearing, discordant if they do not (Ptolemy, 2000: p. 17).

Two different notes are said to be divided by a (musical) interval. How to measure an interval differed for Aristoxenians and for Pythagoreans. The former introduced something similar to a unit of measure that was based on hearing only. The pitches of notes were admitted to vary continuously as points in a straight line. Here clearly a geometric analogy was involved; as the interval is what keeps two points on a straight line apart. When the pitches of two notes are compared, one of which is maintained as fixed while the other is varied, hearing recognizes concordance for certain values of the varying notes, in the sense that the two notes blend and appear as a unique pleasant sound. The first interval for which this occurs was called a fourth, the second a fifth, the third an octave. The interval between the fifth and the fourth was called a tone and was assumed as a unit of measure of intervals.

Pythagoreans operated in a very different way that could be classified as arithmetic. They associated a note with the length of a vibrating string, which could be measured and expressed by a number. When comparing numbers corresponding to different lengths of vibrating strings they realized that the interval, as it is felt by the hear, could be represented by the ratio of the numbers associated with the lengths. In particular a fourth corresponds to a ratio of $4: 3$, a fifth to a ratio of $3: 2$, an octave to a ratio of 2: 1 (today we know that the length of a string, ceteris paribus, is inversely proportional to its frequency of vibration, and a fourth corresponds to two notes whose frequencies have a ration o $4 / 3$ and so on). The composition (sum) of intervals is the product of ratios, their division (difference) the division of ratios. Of course an interval in such an instance has lost all reference to a length, but the name was maintained. Pythagoreans also defined the tone as the difference between a fifth and a fourth, which has the ratio obtained by dividing the ratios of the two intervals, that is $(3: 2):(4: 3)=9: 8^{2}$.

The two concept of the measure of intervals to some extent do clash. For instance Aristoxenians, in their geometric approach, maintained that the fourth measured two and half tones, the fifth three and half and the octave six tones. For the Pythagoreans, however, six tones spanned an interval of $(9: 8)^{6} \simeq 2.002: 1$, greater than an octave. Moreover, the Aristoxenians could divide the tone in equal parts, hearing and geometry allows this; the Pythagoreans could not; arithmetics forbids this because dividing the ratio of 9:8 in two $n$ equal parts requires evaluating the $n$-square root (modern meaning) of 9:8, which is not rational, and thus not an interval.

The tetrachord, an association of notes, is the basis of Greek music. It is made up of a set of four notes of various heights ordered from the lowest to the highest. The lowest and highest notes are separated by an interval of fourth. The intervals among the intermediate notes and the lowest note may vary and defines the genus of the tetrachord. There are three main genera: enharmonic, chromatic and diatonic. In the enharmonic genus the interval between the top of the tetrachord and the highest of the movable notes is high; in the diatonic the interval is relatively small and in the chromatic genus its size is intermediate between those of the other two genera. This is illustrated in Figure 1 where the notes are indicated with the name of the chords in a Lyre: vi $\dot{\alpha} \tau \eta$, the farthest

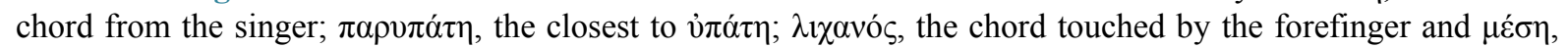
the middle chord.

Tetrachords of the same genus can be joined to constitute a system of tetrachords. They are in conjunction if the lowest note of the upper tetrachord is the same as the highest note of the lower tetrachord; this system is

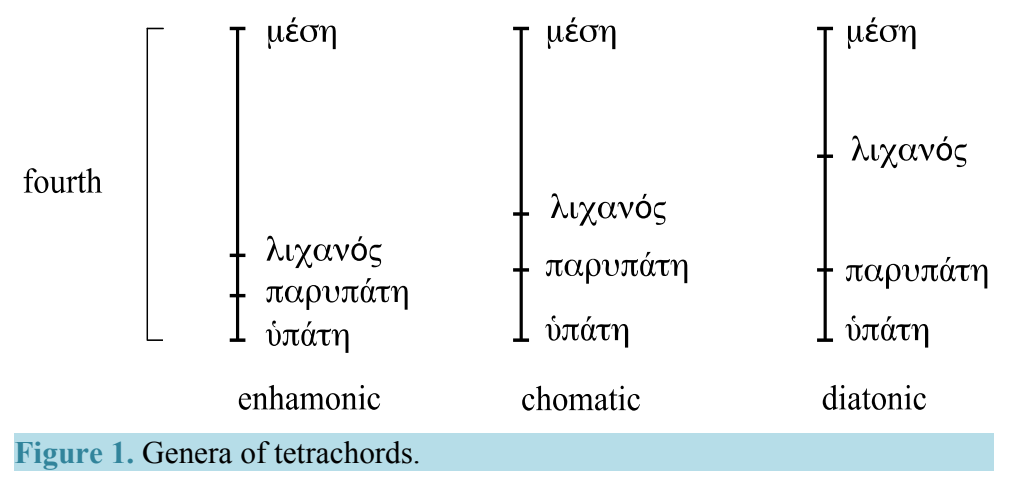

\footnotetext{
${ }^{2}$ The use of modern concepts could be useful in recovering the association of the idea of spatial interval to ratios, using the logarithmic function. If we measure intervals not by the ratio of the pitches but rather by the logarithms of the ratio, we can say that intervals adds, as implied in the Aristoxenian musical theory.
} 
comprised of fourths, with seven notes and six intervals. They are in disjunction if the two tetrachords are separated by an interval; here the system is made up of a fourth and a fifth alternate, with eight notes and seven intervals; two disjoint tetrachords form an octave.

The position of the notes in a disjoint tetrachord justifies the names, fourth, fifth and octave, assigned by the Greeks to the intervals: the interval between the first and fourth note is indeed a fourth (by definition of the tetrachord), the interval between the first and the fifth note is a fifth and the interval between the first and the eighth note an octave.

\section{Empiricist and Rationalist Theoreticians}

As already mentioned, in classical and hellenistic Greece there were two basic approaches to the study of harmonics, the Pythagorean and the Aristoxenian. It must be said that neither school was monolithic and that the work of each did not develop independently of the other. In the following I will present two typical expressions of the two schools from two of the oldest treatises of musical theory. One of these is the Euclidean Sectio canonis, and the other the Aristoxenian Elementa harmonica.

\subsection{Euclid}

The attribution of the Sectio canonis to Euclid (3rd century BC) is controversial, as often occurs for ancient texts; but this is not my concern. The text to which I refer to is that used by Barker who translated it into English (Barker, 1989: pp. 191-207). It consists of a short premise and nineteen propositions (theorems). The premise refers to general physical and epistemological considerations. Sound was associated with motion, "If there were stillness and no movement there would be silence" (Barker, 1989: p. 191). From the nature of motion derives the nature of notes, that are not explicitly defined. Euclid, somewhat vaguely classified motion accordingly to its frequency:

And since of movements some are closer packed, others more widely spaced, those which are closer packed producing higher notes and those which are more widely spaced lower ones, it follows that some notes must be higher, since they are composed of closer packed and more numerous movements, and others lower, since they are composed of movements more widely spaced and less numerous (Barker, 1989: p. 192).

Here packing could be interpreted as occurring in time, so that a closer packed motion has a greater frequency of oscillation. If this interpretation is correct, Euclid was asserting a vision of sound similar to a modern one, a vision not common in ancient Greece, where the association of pitches with speed of air was more common.

Euclid assumed that packing varies in a discrete way, so that notes do, too, and could be represented by numerical discrete values, that is integer numbers. Notes are classified as concordant or discordant. Concordant notes are those that blend and seem almost to form a unique sound, discordant those that do not.

Among notes we also recognize some as concordant, others as discordant, the concordant making a single blend out of the two, while the discordant do not. In view of this, it is to be expected that the concordant notes, since they make a single blend of sound out of the two, are among those numbers which are spoken of under a single name in relation to one another, either being multiple or epimoric [superparticular] ${ }^{3}$ (Barker, 1989: p. 192).

This quotation expresses, with no particular emphasis, the fundamental principle of the treatise, and belongs to the Pythagorean school. This is the principle by which the notes in a concord must be in whole or super-particular ratios of the numbers that represent them. For many Pythagoreans this principle was of a metaphysical nature and derives from the idea that the phenomena of the physical world are governed by numbers and numerical relations that obey particular rules of "symmetry". For other Pythagoreans the principle, albeit maintaining a metaphysical basis, is accepted on the basis of musical practice. In both cases the principle was taken for granted and assumed as a premise of more geometrico argument, typical of mixed mathematics.

Euclid belonged to the second category of Pythagoreans; his mixed position, though not explicitly stated, is clear because he devoted large parts of the Sectio canonis (in particular most of his theorems) to prove that notes considered as concordant by hearing were (by chance?) represented by simple ratios; whereas pure Pythagoreans

\footnotetext{
${ }^{3}$ Super-particular, or epimoric, ratios are those in the form $(n+1) / n$.
} 
would have said that notes corresponding to simple ratios should be concordant a priori.

After the brief preface, Euclid presented the nineteenth propositions. The first nine were purely mathematical covering the theory of proportions. However, in these propositions musical terminology is evident; the term interval is used to indicate a ratio of integers; the union of intervals is an interval given by the product of the ratios of the constituent intervals; the difference of two intervals is the division of the corresponding ratios.

The following list reports sixteen of the nineteen propositions: the last three are left out for their lack of interest or pertinence.

1) If a multiple interval put together twice makes some interval, this interval too will be multiple;

2) If an interval put together twice makes a whole that is multiple, then that interval will also be multiple;

3 ) In the case of an epimoric [super-particular] interval, no mean number, neither one nor more than one, will fall within it proportionally;

4) If an interval which is not multiple is put together twice, the whole will be neither multiple nor epimoric;

5) If an interval put together twice does not make a whole that is multiple, that interval itself will not be multiple either;

6) The duple interval is composed of the two greatest epimoric intervals, the hemiolic (3:2) and the epitritic $(4: 3)$;

7) From the duple interval and the hemiolic, a triple interval is generated;

8) If from a hemiolic interval an epitritic interval is subtracted, the remainder left is epogdoic (9:8);

9) Six epogdoic intervals are greater than one duple interval;

10) The octave interval is multiple;

11) The interval of the fourth and that of the fifth are each epimoric;

12) The octave interval is duple;

13) It remains to consider the interval of a tone, to show that it is epogdoic;

14) The octave is less than six tones;

15) The fourth is less than two and a half tones, and the fifth is less than three and a half tones;

16) The tone will not be divided into two or more equal intervals.

Proposition 10 refers to the octave, which is defined from a musical point of view, as the interval between two notes that shows the maximum concordance according to hearing sole. Nothing is said about its numerical ratio, whose evaluation is the object of the proposition. The octave is also presented as the interval that separates the higher note in a two-octave system from the $\mu \varepsilon \dot{\varepsilon} \eta$, the intermediate note, located an octave below, or the $\mu \varepsilon \dot{\sigma} \sigma$ from the lower note of the system. The statement of the proposition and its proof follows (see Figure 2):

Proposition 10 The octave interval is multiple

Let $\mathrm{A}$ be nēte hyperbolaiōn [the highest note], let $\mathrm{B}$ be mese and let $\mathrm{C}$ be proslambanomenos [the lowest note]. Then the interval AC, being a double octave, is concordant. It is therefore either epimoric [super-particular] or multiple. It is not epimoric, since no mean falls proportionally within an epimoric interval. Therefore it is multiple. Thus since the two equal intervals $\mathrm{AB}$ and $\mathrm{BC}$ put together make a whole that is multiple, $\mathrm{AB}$ is therefore multiple too (Barker, 1989: p. 199).

Euclid began with an empirical observation, hearing, that the two-octave interval is concordant. From his architectonic principle he could deduce that the interval AC must be either multiple or super-particular. But it can not be super-particular because the $\mu \varepsilon \dot{\sigma}\rceil \mathrm{B}$ divides the interval AC into two equal intervals (one octave from the

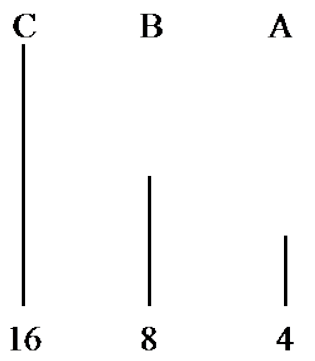

Figure 2. Two joined octave intervals ${ }^{4}$.

${ }^{4}$ Redrawn from (Barker, 1989: p. 199). 
one hand and another octave from the other hand). By proposition 3, however, it is known that a super-particular ratio cannot be divided into two equal ratios, thus the ratio $\mathrm{AC}$ is multiple. By proposition 2 it follows that the ratio $\mathrm{AB}$ (an octave) is multiple. The demonstration appears somewhat contorted and in my opinion contains a petitio principii. That is, it confuses the fact that the $\mu \varepsilon \dot{\sigma} \eta$ is halfway musically with the fact that it is halfway numerically. Nonetheless, it remains quite interesting, as it illustrates how the experimental data is analyzed with the theory of the ratio between numbers.

Demonstrations of other propositions proceed in much the same way. Proposition 13 is worth noting that shows that the range of a tone is expressed by the ratio 9: 8, that is it is epogodic.

Proposition 13. It remains to consider the interval of a tone, to show that it is epogodic.

It is known that if an epitritic [4:3] interval is subtracted from a hemiolic [3:2] interval, the remainder left is epogdoic [9:8]. And if the fourth is taken from the fifth, the remainder is the interval of a tone. Therefore, the interval of a tone is epogodic (Barker, 1989: p. 201).

The starting point is the implicit definition of the interval as the distance between a fifth and a fourth (their difference). As proposition 11 (and 12) show that the intervals of fourth and fifth have ratios of 4:3 and 3:2 respectively, the proof of proposition 13 is immediate because the subtraction of the intervals is equal to their division, so: $(3: 2):(4: 3)=9: 8$.

Worthy of note are propositions 14 and 15, later emphasised by Ptolemy, to counteract the thesis that he attributed to Aristoxenus, according to which the octave is six tones, the sum of a fourth of two and a half tones, and a fifth of three and a half tones. Proposition 16 shows the limit of the arithmetic approach to harmonics. A tone cannot be divided into two equal intervals because a super-particular ratio cannot be divided into two equal ratios; this would correspond to the evaluation of the square root (modern term), which is irrational and thus not a ratio.

\subsection{Aristoxenus}

Aristoxenus (c. 360-c. 320 BC) was an important student of Aristotle; he even aspired to succeed him in Liceum, however with no success. He is considered (one of) the most important figures in the history of Greek musical theory. Ingemar Düring, the editor of Ptolemy's Harmonics, observes that “Aristoxenus's theory of music is revolutionary. It rests on the fundamental principle that the human ear is the sole arbiter of the correctness of pitches and harmonic function" (Düring, 1956). He was a prolific writer in philosophy, although little interested in metaphysics. He wrote several treatises on music and, among these, the Elementa harmonica, that has come down to us relatively intact. At least two editions exist in English; one, older, which also contains the Greek text (Aristoxenus, 1902), and a more recent version (Barker, 1989). There is also a large commentary (Laloy, 1904) and quite good Italian edition (Aristoxenus, 1954).

The Elementa harmonica is the most ancient work known on music and is a repository of ancient thought and accomplishments. The extant text is divided into three books: the first two are partially overlapping and report the main elements of theory and epistemology. The third book contains the demonstration of some propositions of a musical nature. Aristoxenus' epistemology is strongly influenced by that of Aristotle; harmonics must be based on principles considered true and evident. Like Aristotle he assumed that during a demonstration it was not possible to move from one genus to another (prohibition of metabasis):

Since every science that consists of more than one proposition should adopt first principles from which the things dependent on these principles can be demonstrated, we must adopt such principles, bearing the following two points in mind. We must ensure, first, that each of the fundamental propositions is true and evident [emphasis added], and secondly that each is such as to be accepted by perception as belonging among the primary parts of harmonic science: for whatever demands demonstration is not fundamental. And in general we must be very careful, as we set out, not to slip into extraneous territory by beginning from a conception of sound as a movement of the air, and equally not to turn back too soon and leave out many things which belong to the subject (Barker, 1989: p. 159).

Principles of harmonics should be derived directly from harmonics itself and not from other sciences such as acoustics, for instance.

Both the first two books try to clarify what is harmonic; meanwhile, it does not coincide with music but only 
affects the organization of musical intervals:

Harmonics is only a part of the musician's accomplishment, as are the sciences of rhythm, metre and instruments.

We must therefore give an account of harmonics and its parts. It is to be understood, speaking generally, as the science which deals with all melody, and enquires how the voice naturally places intervals as it is tensed and relaxed. For we assert that the voice has a natural way of moving, and does not place intervals haphazardly (Barker, 1989: p. 149).

Harmonics depends on two things, hearing and reason. And the sense perception, hearing, plays a major role, which is not the case with mathematics:

The geometer makes no use of the faculty of perception: he does not train his eyesight to assess the straight or the circular or anything else of that kind either well or badly: it is rather the carpenter, the wood-turner, and some of the other crafts that concern themselves with this. But for the student of music accuracy of perception stands just about first in order of importance, since if he perceives badly it is impossible for him to give a good account of the things which he does not perceive at all (Barker, 1989: pp. 150-151).

Aristoxenus also stated the importance of memory to compare what was past with what is present:

Comprehension of music comes from two things, perception and memory: for we have to perceive what is coming to be and remember what has come to be. There is no other way of following the contents of music (Barker, 1989: p. 155).

He divided harmonics into seven parts. The first concerns the distinction between genera (inside the tetrachord), the second the distinction between intervals, the third notes; the other parts relate to more complex organizations, such as the union of more tetrachords.

In Book I, sound is presented as a process in which pitches may vary continuously from top to bottom and vice versa, with an image that evokes the movement of a point on a line. There is obviously an upward and downward physical limit to pitches both for the generation and for the ear. However, Aristoxenus rather than the absolute value of the pitch of a note, refers to the interval of two notes. For example, according to him, the ear cannot clearly distinguish an interval under a fourth of a tone. After this introduction he went on to define the note. A note in essence is the stabilization of the sound on a single pitch.

Now that this is understood we must say what a note is. To put it briefly, a note is the incidence of the voice on one pitch: for it is when the voice appears to rest at one pitch that there seems to be a note capable of being put into a position in a harmonically attuned melody. That, then, is the sort of thing a note is (Barker, 1989: p. 13).

The interval is what is limited by two notes that do not have the same pitch, in analogy to the interval of a straight line which is defined by two points. The word Aristoxenus used for interval is $\delta$ ió $\sigma \tau \varepsilon \mu \alpha$, the same used by Euclid in the Elements (Barbera, 1977). Intervals are classified with respect to their size, if they are concord or discord, if they are composite or in-composite, with respect to the genus to which they belong.

Aristoxenus said that there were eight magnitudes of concords, though he referred only to three of them. The smallest is the fourth, the second the fifth, the third is the sum of a fourth and a fifth, that is an octave. Other concordant intervals are obtained by adding an octave to a concordant interval.

We must explain first that the addition of any concordant interval to the octave makes the magnitude resulting from them concordant. This is a quality intrinsic and peculiar to the concord of the octave, for whether the concord added is smaller than it or equal or greater, the result of the combination is concordant (Barker, 1989: p. 160).

That by which the fifth is greater than the fourth is named a tone. Moreover the fourth is two and half tones and the fifth three and a half tones. Note that Aristoxenus never explicitly said that an octave consists of six tones, though this can be deduced from his writings. A tone may be divided in a manner that intervals result melodic into two parts (halftone), three parts, four parts. However he accepted that from a purely abstract point of view there is no limit in the division, as occur in a geometric line. A tone defines a metric in Aristoxenus' harmonics, so that it becomes mathematical. 
At the end of Book II Aristoxenus laid down the principle on which his whole theory of harmonics was based; how the intervals should be organized so that they result melodic:

We must next give an account of the first and most indispensable of the conditions that bear upon the melodic combination of intervals. Let it be accepted that in every genus, as the melodic sequence progresses through successive notes both up and down from any given note, it must make with the fourth successive note the concord of a fourth or with the fifth successive note the concord of a fifth. Any note which fulfils neither of these conditions must be considered unmelodic relative to all the notes with which it fails to form concords in the numerical relations mentioned (Barker, 1989: p. 167).

Alongside this architectonical principle there is another, which concerns how two tetrachords are joined:

Similar to it, in a way, is the principle which governs the positioning of tetrachords in relation to one another. Tetrachords that belong to the same system must have one or other of two properties. Either they must be concordant with one another, so that each note of the one forms some concord with the corresponding note of the other, or they must both be concordant with the same tetrachord, each of them being continuous with the one with which they are concordant, but not in the same direction (Barker, 1989: p. 167).

These two principles are largely experimental in character, even if they are mediated by reason. They do not reflect, however, the Aristotelian epistemology he declared. Indeed its principles can be considered as true but they were certainly not obvious.

From a reading of the first two books of Aristoxenus, what emerges is a scholar who adopted a rigorous and fairly concise language, closer to that of mathematicians than to philosophers; his arguments were based on natural logic and not on syllogism, and in most cases they are sufficiently stringent.

Aristoxenus did not repudiate the use of mathematics; he only maintained that it could not be of any help in establishing the principles of harmonics, as the Pythagoreans did. Having introduced a metric, the tone, he could measure musical intervals and can prove theorems with the aid of geometry, and thus, as already noted, could move in the root of mixed mathematics. Barker in (Barker, 1989: p. 16) criticizes Aristoxenus for his claim that tone could be divided into many parts-Aristoxenus also mentioned intervals as small as one twelfth of a tone, much smaller than the smallest melodic interval of one fourth of tone- because he did not dispose of any empiric method to verify this division; and because he did not possess a criterion to hear an interval of one fourth of tone he was not justified in claiming that it was the smallest melodic interval. I do not share Barker's criticism and believe that, in any mixed mathematics, aspects are suggested that cannot be verified experimentally, but this notwithstanding can still be classified as empiric.

How Aristoxenus presented his measure of intervals, always made reference to the three concords, the fourth, the fifth and the octave, the only ones that the ear can distinguish very clearly. For instance to find a note E, two tones below a given note A (see Figure 3), one can move by a fifth and a fourth alternatively, as explained in the quotation:

Thus, if we have the task of constructing from a given note a discord such as a ditone downwards (or any of those which can be constructed by means of concords) we should construct from the given note [A] a fourth upwards [B], from there a fifth downwards [C], then another fourth upwards [D], and then another fifth downwards $[\mathrm{E}]$. In this way the ditone $[\mathrm{AE}]$ downwards from the given note will have been constructed (Barker, 1989: p. 167).

Using a variant of this approach Aristoxenus could measure the interval of a semitone (see below), but in no way could he measure smaller intervals.

One important reason for which Aristoxenus thought that mathematics could not exhaust the study of harmonics, was that the musical value of a set of notes is not only given by the measure of their intervals, but it is

\begin{tabular}{ccccc}
\hline & + & & & \\
\hline $\mathbf{E}$ & $\mathrm{C}$ & $\mathrm{A}$ & $\mathrm{D}$ & $\mathrm{B}$ \\
4 & 2 & 0 & 3 & 1
\end{tabular}


also given by its function in a melody, by its dynamics. For instance, the intermediate notes of a tetrachord of the same genus could be described by different (infinite) mathematical ratios and thus they could be considered as different notes. However, the ear, if the variation of the pitches is not very high, hears the notes as belonging to the same genus, and this could not be explained by mathematics (Barker, 1978; Barker, 1989: pp. 12, 161163).

Book III concerns propositions (theorems) to be proved starting from assumed principles. It parallels Euclid's Elements. There are 27 propositions. Some of the most relevant are listed here.

1) Successive tetrachords are either conjunct or disjunct.

3) In variations of genus it is only the parts of the fourth that change, while the interval peculiar to disjunction is unaltered.

8) Two ditones will not be placed in succession.

9) In the enharmonic and chromatic, two tones will not be placed in succession.

11) In this same genus, two semitones will not be placed in succession.

To show how Aristoxenus' argues this, below is a proof of proposition 1 and the proposition considered in Book II, according to which a fourth is composed of two and half tones.

Successive tetrachords are either conjunct or disjunct.

Let it be called 'conjunction' when two tetrachords, successive in the melodic series and with the same arrangement [schema], have in the middle a common note; and let it be called "disjunction" when between two tetrachords, successive in the melodic series and with the same arrangement, there lies a tone. That one or the other of these must apply to successive tetrachords is clear from the assumptions we laid down. When the notes four places apart in a continuous series form the concord of a fourth they will produce conjunction, and when those five places apart from a fifth they will produce disjunction. But the notes must fulfil one or other of these conditions, so that successive tetrachords must have one or the other of the properties mentioned (Barker, 1989: p. 170).

Aristoxenus used his principle by which, in the conjunction of two tetrachords, as in any musical scale, the distance of four successive notes should have an interval of a fourth, that of five successive notes an interval of a fifth. However the first case is that of a conjunct tetrachord, the second that of a disjunct tetrachord. Considered otherwise one could turn the proposition into the following problem: how to merge two tetrachords so that their union respects the principle of melody set by Aristoxenus? The answer is: two tetrachords must be either conjunct or disjunct, tertium non datur.

The fourth consists of two and a half tones.

The question whether we were correct in the assumption, which we made in our introduction, that the fourth consists of two and a half tones, can be investigated most accurately in the following way. Take a fourth, and starting from each of its extremes in turn, mark off a ditone by means of concords. It is clear that the remainders are equal, since equals have been taken from equals. Next, take a fourth upwards from the lower bounding note of the upper ditone, and take another fourth downwards from the upper bounding note of the lower ditone. It is clear that next to each of the notes which bound the resulting systema there will be two consecutive remainders which must be equal, for the reasons stated before. When this construction has been set up, we must bring to the judgement of perception the outermost of the notes that have been located. If they appear to perception as discordant, it will be evident that the fourth is not two and a half tones: but if they sound the concord of a fifth, it will be evident that the fourth is two and a half tones. For the lowest of the notes constructed was tuned to make the concord of a fourth with the upper bounding note of the lower ditone, and the highest of the notes constructed has turned out to form the concord of a fifth with the lowest; so that since the difference is a tone, and since it is divided into equal parts, each of which is a semitone and is also the excess of a fourth over a ditone, it is clear that the fourth consists of five semitones (Barker, 1989: pp. 168-169).

Aristoxenus's proof assumes that intervals could be added together to obtain larger intervals, just as with the line segments. This is not only developed on the basis of the premises and established principles but, at a certain point, it also requires experience to prove a crucial point. The demonstration can be better understood if reference is made to geometry. In Figure 4, the segment $\mathrm{AB}$ represents the interval of a fourth, which is concordant by definition. Point $\mathrm{C}$ is a pitch distant a ditone from $\mathrm{B}$ (that is the segment $\mathrm{CB}$ is a ditone) $)^{5}$; similarly the point

${ }^{5}$ Aristoxenus did not consider the 'experimental' construction of a ditone interval to be a problem, as shown in Figure 4. 


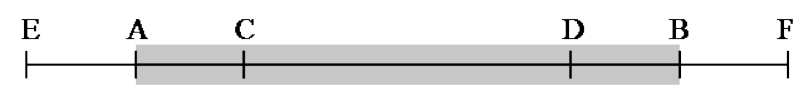

Figure 4. A fourth $[\mathrm{AB}]$ is composed of two $[\mathrm{AD}]$ and half [DB] tones.

$\mathrm{D}$ is a pitch distant two ditones from A. Obviously $\mathrm{AC}=\mathrm{BD}$. Aristoxenus then considered pitches $\mathrm{E}$ and $\mathrm{F}$ a fourth away from $\mathrm{D}$ and $\mathrm{C}$ respectively. At this point he declared the need for a musical experiment, to see if the interval EF is concordant. And without being particularly clear, he stated that EF is in fact concordant. Thus it is easy to show that EF is a fifth because it is a concord closer to a fourth than it is to an octave (this also should be an experimental result) and there are no other nearby concords. But if $\mathrm{EF}$ is a fifth, by definition of tone, DF is the length of the tone (difference between $\mathrm{EF}$ and $\mathrm{AB}$ ), $\mathrm{DB}$ is a semitone (half of a tone) and $\mathrm{AB}$, the sum of the ditone $\mathrm{AD}$ and of the half tone $\mathrm{DB}$, is two tones and a half.

Aristoxenus's proof, though very interesting is certainly questionable. In order to be considered a true demonstration more geometrico, the result of experimental observations should appear in the premise. However, this is only a defect of a formal kind and could be overlooked. What perplexes the modern reader is that the proposition to be proved is false if interpreted with modern categories and instruments, where pitches are considered as frequencies and measured in Hz. This issue is discussed in (Litchfield, 1988). However, it is this author's opinion that to judge Aristoxenus's demonstration as wrong is questionable and the error, if any, can can be found in the experimental results; indeed a very accurate experimentation, carried out by using electronic device, shows that EF is not a fifth, so the error in Aristoxenus's proof is of an experimental and not logical nature. However, an experiment only using the ear could not give a definitive verdict. Therefore, Aristoxenus's results, instead of being wrong should simply be considered approximate ${ }^{6}$.

\section{Ptolemy's Harmonica}

Among the great treatises of Ptolemy (c. 100 AD-c. 175 AD), such as the Almagestum and the Geographia, the Harmonica is the least fortunate. The existing text is not reliable. In particular the last three chapters are missing and authenticity of the third as a whole is doubtful (Ptolemy, 2000: p. XXX). When it became available in Europe, it was no more than a historical document, and musical theory had evolved quite differently?

The treatise is composed of three books each divided into sixteen chapters. In Book I Ptolemy tackled the fundamentals of the subject, defined epistemology, and criticized previous approaches, in particular those of the schools of Pythagoras and Aristoxenus. It was here that he put forward his theory on the tetrachord. Book II fully develops his theory of music. Book III describes the concepts of musical harmony and their relation to the human soul and to the heavens.

References concerning epistemology are scattered throughout the treatise. From the very first pages Ptolemy's efforts to indicate that his epistemology is not only about music but about all of sciences are quite clear. However, in the Harmonica the epistemological positions - surprising for us today - are fully explicit, more than they were for example in the Almagestum, which could appear to be a much more scientific text. Ptolemy seeks an agreement between a mathematical theory, made explicit by a number of assumptions on numerical relationships, and experience, which concerns the consent of the human ear to sounds, in the sense that it finds them somehow melodious. Ptolemy was convinced that this agreement should exist because nature itself has an intrinsic harmony. It is man's purpose to recognize this through the use of reason and senses.

For in every subject it is inherent in observation and knowledge to demonstrate that the works of nature have been crafted with some reason and prearranged cause and completed not at all in random or as it happened, particularly in its most beautiful constructions which are simply those of the sense perceptions more

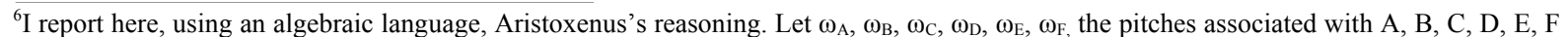
respectively (measured for instance by the logarithm of their frequencies expressed in $\mathrm{Hz}$ ), $T$ is the interval of a tone and $F$ the interval of a fourth. By construction it is: $\omega_{\mathrm{C}}=\omega_{\mathrm{B}}-2 T ; \omega_{\mathrm{D}}=\omega_{\mathrm{A}}+2 T ; \omega_{\mathrm{E}}=\omega_{\mathrm{D}}-F ; \omega_{\mathrm{F}}=\omega_{\mathrm{C}}+F$. Simple calculation gives: $\omega_{\mathrm{F}}-\omega_{\mathrm{E}}=3 F-4 T$. Assuming $\omega_{\mathrm{F}}-\omega_{\mathrm{E}}=F+T$, that is a fifth, the previous relation gives: $F+T=3 F-4 T$, or $F=2.5 T$, thus Aristoxenus thesis.

${ }^{7}$ The Greek version was edited in 1930 by Ingemar Düring (Düring, 1930: p. 319) its history and translation in the late Middle Ages and in the Renaissance are documented respectively in (Manolova, 2014) and (Palisca, 1985). To my knowledge there are two modern English translations, one by Andrew Barker (Barker, 1989), the other by Jon Solomon (Ptolemy, 2000). Here Solomon's translation and critique is largely referred to, with some reference to Barker's that is more accessible.
} 
closely related to reason-sight and hearing (Ptolemy, 2000: p. 8).

The roles of reasons and hearing are distinct "hearing is criterion for matter and conditio, while reason is the criterion for form and causes" (Ptolemy, 2000: p. 3). Ptolemy specified that the role of hearing is "discovering what is approximate and accepting what is exact", while the role of reason is "accepting what is approximate and discovering what is exact". That is, given two or more sounds, the role of hearing is to discover the approximate ratio of their pitches for which the sounds appear concordant. Then reason examines the ratios and corrects them if they appear irrational, that is contrasting with the hypothesis of harmonics. Subsequently these rationally modified ratios and mathematical inference from them are subject to hearing that should give its assent. Ptolemy specified that sense perception is characterized by incertitude:

Perception, on the other hand, is of constantly mixed and fluctuating matter, so that on account of its instability neither the perception of all men nor that of the same men always observes the same thing in what has remained the same. Perception needs as its crutch, as it were, the educational assistance of reason (Ptolemy, 2000: p. 4).

and that it can distinguish between similar concords even though the difference is minimal at a first glance.

Just as a circle described by one's eye alone has often seemed to be accurate until one drawn by reason redirects the eye to recognize what is truly accurate, if some specific difference of sounds is perceived by the hearing alone, it will then for a time seem neither to fall short nor to be excessive; yet it will frequently be proved not to be so when one selected according to the appropriate reason is heard (Ptolemy, 2000: p. 4).

In any case there is a limit to human perception. But a continuous hearing can help perceive even very small differences.

In the comparison of smaller parts, more of the deficiency will be concentrated and now made detectable in them, and even more so in still smaller ones. The reason is that something which is just once quite short of the truth and cannot make the amount of its shortness perceivable by few comparisons, will when a number of comparisons are made be most noticeable and comprehensible to all (Ptolemy, 2000: p. 5).

This quotation is interesting as it refers to actual experimentation, similar to that carried out in a modern laboratory, where an experience is repeated many times to evidence the regularity of a phenomenon.

\subsection{Ptolemy's Musical Hypotheses}

Ptolemy defined his musical hypotheses first in the negative sense, stating how they differed for those of the Pythagoreans and Aristoxenians. Those regarding Pythagoreans are of greater interest and only these will be remarked ${ }^{8}{ }^{8}$. Ptolemy said that their rational criteria were quite satisfactory, but they fail in some aspects; in particular they were not able to furnish rational criteria for all concords; for instance they could not justify the concord 8:3.

Ptolemy first solved this particular problem, by observing that the interval 8:3 is the conjunction of an octave and a fourth $(8: 3=2: 1 \times 4: 3)$. Assume three notes, A, B and C. A and B are separated by an octave, B and C by a fourth; consequently $\mathrm{A}$ and $\mathrm{C}$ are separated by an interval of 8:3. Based on hearing, $\mathrm{A}$ and $\mathrm{B}$ are nearly the same. Thus if there is concordance between B and C (and this is the case), there also should be concordance between A and C (Ptolemy, 2000: p. 20).

Then Ptolemy put forward his hypotheses about ratios for which the notes that are not concordant are at least melodic. Ptolemy's interest is centered on intervals lower than a fourth, those in a tetrachord. His position is quite articulated. However it is not my goal here to fully grapple with his ideas, to this purpose reference can be made to (Barker, 2006). In essence he proposed the following hypotheses that that may be classified as rational as they can be derived by reason according to principles of symmetry and simplicity. They are summed up in this quotation:

In a word, the homophones would come from both the first multiple ratio and those measured from it.

Consonances are the first two superparticular ratios and those composed from them plus the homophones,

while the emmelic are those super-particular ratios after the sesquitertian [4:3] (Ptolemy, 2000: p. 24).

${ }^{8}$ Probably Ptolemy is referring to Architas of Tarentum (Barker, 1994: p. 13). 
Where the homophones are separated by octave intervals, the consonances are the first concords, the fourth and fifth (the two super-particular ratios); then the simply melodic intervals follow which are super-particular ratios smaller than a fourth. Ptolemy also suggested a criterion according to which the super-particular ratios $(n$ $+1) / n$ with the smaller values of $n$ are more melodic.

For the same reason, those ratios making their divisions nearly in half are more emmelic, as are those differences limiting greater, simpler parts than their excesses, since these, too, are nearer equality just as is primarily the half, and then the third and each of the succeeding ratios (Ptolemy, 2000: pp. 23-24) ${ }^{9}$.

To these fully rational criteria Ptolemy added another of an empiricist nature that holds for the arrangement of the two moving notes of the tetrachord. According to this they should be organized so that of the three intervals the lowest is smaller than the other two:

Agreeing with our sense perceptions, we assume as an equally common element in the three genera that the following intervals of the three magnitudes are smaller than each of the remaining intervals; and it is particular to the genera which have pyknalfootnote \{Singular pyknon; two notes in the tetrachord very close each other. that the two bottommost intervals be smaller than the topmost interval, while it is particular to the apyknon genera that no interval be greater in magnitude than that of the two remaining intervals (Ptolemy, 2000: p. 48).

Ptolemy was not troubled about mixing rational and empiricist principles; his epistemology permitted this, organized as it was in two distinct phases. The first inductive phase forwards the hypotheses. Here Ptolemy is completely free in his choice, that could even be made by chance -though this would be quite a modern approach. So any source could be assumed for the hypotheses made. In the second deductive phase theorems are derived from the hypotheses, assumed as principles of a more geometrico argument. Theorems which consist in propositions to be verified by hearing. If consent is gained the hypotheses are validated independently of how they were obtained.

Ptolemy believed that his criteria of melody had absolute value. For him it is part of human nature to distinguish which sounds are melodic and which are not. Today it is rather generally accepted that musical taste is largely influenced by culture. Specifically what Ptolemy and the Greeks considered pleasing melodies, if the reconstruction of Greek sounds are reliable, are not such for us. The following anecdote, I think, will clarify the idea.

Some years ago, for example, Sir Robert Stewart delivered a lecture in Trinity College, Dublin, on the Music of Distant Times and Places; and illustrated it by specimens from various nationalities and periods, an ancient Greek hymn being included in the number. It was the unanimous verdict of all the musicians present that, while the music of the less civilized nations was often crude, barbarous, and monotonous in the highest degree, the Greek hymn stood quite alone in its absolute lack of meaning and its unredeemed ugliness; and much surprise was expressed that a nation which had delighted all succeeding generations by its achievements in the other arts should have failed so completely in the art which it prized and practiced most (Aristoxenus, 1902: Introduction).

\subsection{The Harmonic Canon}

The fundamental assumption of harmonics is the representation of pitches through numeric values and relations between pitches through ratios. But since numbers cannot be found in sounds they are to be found in their causes. More precisely these are found in observable and measurable aspects of musical instruments.

Because circumstances are similar regarding in the case of sounds and hearing, there is a need, as there is for sight, of some rational criterion for them from the appropriate instruments, just as the straight edge has, so to speak, need of a ruler, and the circle and the measurement of its parts have need of a compass. In the same way, the hearing, which is, along with sight, for the most part a messenger for the theoretical and rational aspect of the soul, needs some reasoned approach, too, for those things its nature cannot judge accu-

${ }^{9}$ Barker translates this piece as follows: "Of these ratios too, those that make divisions most nearly into halves must be more melodic, for the same reason as are all those whose differences contain larger simple parts of the things that are exceeded; for these, too, are nearer to the equal, just as the half is nearest of all, then the third, and then each of the others in succession" (Barker, 1989: p. 290). 
rately, which it will not contradict but confirm as correct.

$[\ldots]$

The tool of this type of approach is called the harmonic canon [emphasis added] (Ptolemy, 2000: p. 6).

After some fairly convincing arguments Ptolemy concluded that the most appropriate instrument to identify the ratios between tones is the monochord; it is simple to construct and is controllable, more than the aulos for instance ${ }^{10}$, where the height of the sound also depends on the power of the player, and this is not observable. The best observable magnitude in the monochord-canon is its length and the numbers that describes it serve as a measure of the height of the tones.

Ptolemy devoted much thought to the description of the monochord. In essence it consists of a string of a suitable material, for instance the same material as the chords of the lyra, fixed at two ends. Plucking or drawing a bow, the string produces a sound whose pitch depends on various parameters. Among them Ptolemy specified; the length of the string, the diameter of the section, the density of the matter. Only subsequently did Ptolemy mention tension (notice that here, and in the following, tension means force of traction, not to be confused with stress, that is force per unit of surface).

There are three reasons for the difference between high and low sounds; the density, the diameter, and the lengths of the strings. The higher sound results from a denser and thinner string and a shorter length; tension here takes the place of density, for it creates greater tension and hardens also what would be similar if the string had a shorter length (Ptolemy, 2000: pp. 37-38).

Here Ptolemy said that the greater the density-a term to which he associated, in an intuitive form, the present meaning - the higher the sound. Actually the contrary is true. The reason for this error can be explained by the fact that when Ptolemy compared sounds produced by percussion of bronze and wood, the former for him produces higher sounds because it is denser (Ptolemy, 2000: p. 12) ${ }^{11}$. With some imprecision he added that tension (force) and diameter could compensate each other. That is strings with different diameters sound the same if their tension is proportional to the diameter. Actually the proposition is true assuming the area and not the diameter of the cross section of the string ${ }^{12}$.

The monochord described by Ptolemy is shown in Figure 5(a) and described as follows:

Imagine a canon along the straight line $\mathrm{ABCD}$. At its ends on each side are bridges equal and alike forming as much as possible spherical surfaces under the strings. F marks the center of the aforementioned surface on the line $\mathrm{BE}$, and $\mathrm{H}$ similarly marks the center on $\mathrm{CG}$, while the signs $\mathrm{E}$ and $\mathrm{G}$ are understood to mark the bisections of the two circular surfaces (Ptolemy, 2000: p. 26).

How the monochord is presented and commented on is somewhat difficult to understand. Moreover, the use of two cylindrical solids to define the length of the string is unconvincing; surely no luthier would adopt this method. The presentation made by Ptolemy can only be justified by his need to formulate the problem from a formal point of view, to justify theoretically that the contact between the rope and medium terms precisely at the tangent points $\mathrm{E}$ and $\mathrm{G}$.

To measure the length of the string Ptolemy referred to a calibrator (a graduated rule), that fits "to the string transferring the length EG on it, so that we can make our measurement more easy" (Ptolemy, 2000: p. 27). Then Ptolemy spoke of a bridge to be put in an intermediate position, similar to these at the end E, G, but slightly higher. This ensured a good contact between the string and the bridge, effectively separating the string, as illustrated in Figure 5(b).

I must confess that I do not understand what Ptolemy's purpose was when he proposed to test the bridge in different positions. His goal should have been to check the construction of the monochord; in particular, to check if the string is homogeneous. Dividing the string in half and by vibrating the two halves separately if the string is uniform along its length one should hear the same sound, because the two halves are of the same length and the same tension. In addition to this type of verification other can be done. For example, by dividing the rope in a ratio of 4:3, the shorter string produces a sound that is a fourth interval far from the longest and the

\footnotetext{
${ }^{10}$ The aulos is a wind instrument with double reed.

${ }^{11}$ Actually the difference in sound mainly depends on the greater stiffness of bronze.

${ }^{12}$ The frequency of a vibrating string is inversely proportional to length and diameter, directly proportional to the square root of ratio between tension and density, or alternatively inversely proportional to length and directly proportional to the square root of the ratio between tension and the product of area by density.
} 


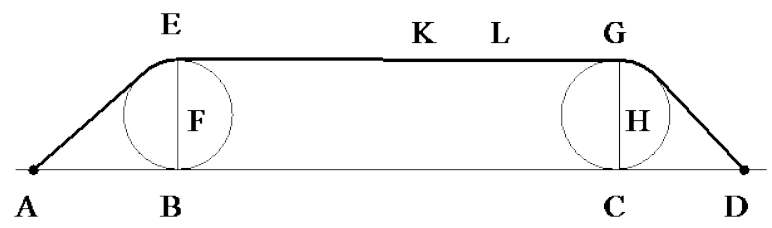

(a)

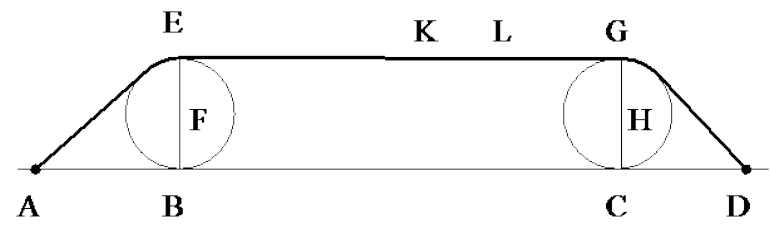

(b)

Figure 5. (a) Basic monochord ${ }^{13}$; (b) monochord with and intermediate bridge.

two strings can be made to vibrate at the same time so that the concordance can be perceived. Similarly, by dividing the rope in the ratio 3:2 one can play a fifth, in the ratio 8:3 an octave and a fourth $(2: 1 \times 4: 3)$.

Once the correct construction of the monochord is verified, it can be used to conduct musical experiments. Ptolemy expressed no doubts about this, even though the modern reader may remain somewhat skeptical about whether it makes sense to verify by way of experiment mathematical hypotheses that do not seem to admit alternatives. Today, but probably even then, the monochord is mostly used to demonstrate to students the goodness of the theory of harmony based on ratio, for particular values of ratios; for example 2:1, 4:3, 3:2. If for some reason hearing suggests a lack of concordance, we immediately believe that the canon has serious construction defects. Ptolemy seemed genuinely convinced, at least in some situations, that he was carrying out true experiments and even went so far as to show the reader how to do these. However, even though Ptolemy would never have conducted musical experiments himself, his epistemological proposal was extremely clear and was considered applicable, for example, to astronomy where the possibility that the experiment (observation) falsifies the theory is more plausible.

Ptolemy proposed tests to show that certain assumptions by Aristoxenus on the composition of musical intervals were wrong. In particular, he claimed that the hypotheses for which a fourth interval is constituted by two and a half tones, and one octave by six tones are false. Here I will not argue whether Ptolemy is falsifying the theory of Aristoxenus, as the two theories are essentially incommensurable; I will limit myself to showing that Aristoxenus's theory as reported by Ptolemy is falsified. My only comment is on the proof that the octave is not the sum of six tones, because in this case there is no need to define the semitone, and thus the proof is simpler. If the definition of the interval of a tone of Ptolemy is accepted, represented by the ratio 9:8, his conclusion is straightforward and was already found in Euclid's Sectio canonis (see previous sections). In fact it is $(9: 8)^{6} \simeq$ $2.002: 1$ and thus slightly greater than the octave $(\$ 2: 1 \$)$. Ifootnote \{Note that for the definition of an interval Ptolemy has him state that the disjoint union of two tetrachords provides one octave, even if it is not the sum of six intervals. In fact the two tetrachords each provide an interval of $4: 3$; the tone between them defines an interval of $9: 8$, the union of the three intervals gives $(4: 3) \times(4: 3) \times(9: 8)=2: 1^{14}$.

Ptolemy argued that this difference could be observed experimentally. In order to do this he suggested building a tool of eight strings (octachord canon), the first seven separated by an interval of one tone, the last equal in length to half of the first string (then separated from it by an octave). The purpose of the experiment, I believe, is the empiric verification of the difference between the union of six tones and the octave. The use of multiple strings should have the function of being able to achieve a better control of the division into six tones. Ptolemy also discussed, albeit very briefly, the possibility of tuning the six strings separately, adjusting the force to which they are subject.

\footnotetext{
${ }^{13}$ Redrawn from (Ptolemy, 2000: p. 26).

${ }^{14}$ Note that for the definition of an interval Ptolemy has him state that the disjoint union of two tetrachords provides one octave, even if it is not the sum of six intervals. In fact the two tetrachords each provide an interval of 4:3; the tone between them defines an interval of 9:8, the union of the three intervals gives 4:3 $\times 4: 3 \times 9: 8=2: 1$.
} 
Together with monochord and octachord canons, Ptolemy proposed another instrument "which was devised by theoreticians" (Ptolemy, 2000: p. 66) ${ }^{15}$ the helicon, which is shown in Figure 6 and described in the following quotation:

They propose a rectangle ${ }^{16} \mathrm{ABCD}$, halve $\mathrm{AB}$ and $\mathrm{BD}$ at $\mathrm{E}$ and $\mathrm{F}$, connect $\mathrm{AF}$ and $\mathrm{BGC}$, and parallel to $\mathrm{AC}$ they lead EHK through $\mathrm{E}$ and LGM through $\mathrm{G}$. In such a configuration $\mathrm{AC}$ will be double each of $\mathrm{BF}$ and $\mathrm{FD}$, as will each of these be double $\mathrm{EH}$ since also $\mathrm{AB}$ is double $\mathrm{AE}$, so that also $\mathrm{AC}$ will be quadruple $\mathrm{EH}$ and sesquitertian of the remainder $\mathrm{HK}^{17}$ (Ptolemy, 2000: p. 66).

The four strings AC, BK, LM, BD, all similar and equally taut, are divided by the inclined bridge AF in portions with various ratios to each other; thus many consonances and the whole tone could be revealed: The fourth (ratio 4:3) is formed by AC:HK, as well as GM:FD and LG:EH. The octave by AC:BF (or FD) and GM:LG. The octave plus a fourth (3:1) by AC:EH, the whole tone (9:8) by HK:GM.

The advantage of this instrument with respect to the monochord is that there is no need to move the bridge to reveal the various concordances.

A variant to the helicon is suggested in Figure 7. Here, there are still four strings, AC, LG, NH, BD, and a bridge $\mathrm{AE}$, where $\mathrm{E}$ is such that $\mathrm{AE}=2 \mathrm{AB}$; there is no need that $\mathrm{ABCD}$ be square. The intermediate chords are positioned by measuring their distances from $\mathrm{E}$. If $\mathrm{P}$ is a generic point on $\mathrm{EC}$, the ratio $\mathrm{EC}$ : $\mathrm{EP}$ defines the ratio of the length of the strings with respect to AC. For instance, if $\mathrm{P} \equiv \mathrm{D}$, the chord $\mathrm{DB}$ is divided in $\mathrm{F}$, so that $\mathrm{AC}$ : $\mathrm{DF}=\mathrm{EC}: \mathrm{ED}=2: 1$; for $\mathrm{P} \equiv \mathrm{H}$, the chord $\mathrm{HN}$ is divided in $\mathrm{M}$, so that $\mathrm{AC}: \mathrm{HM}=\mathrm{EC}: \mathrm{EH}$ (for instance 3:2). The bridge AE can be moved to EO, with AC:AO a proper ratio. Thus different sets of ratios of pitches can be easily obtained.

The advantage of the first form of helicon (that shown in Figure 6), is that without moving the strings a large set of pitches can be achieved; this is the same advantage both helicons have with respect to the canon. Ptolemy stresses that moving a string creates problems from a practical point of views, needing tuning each time. The advantage of the second form of the helicon is that thanks to the particular arrangement of the bridge internal

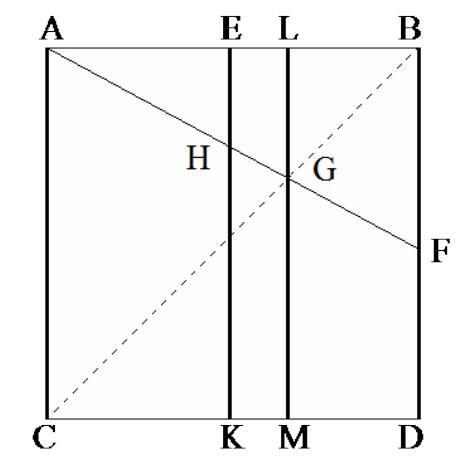

Figure 6. The helicon ${ }^{18}$.

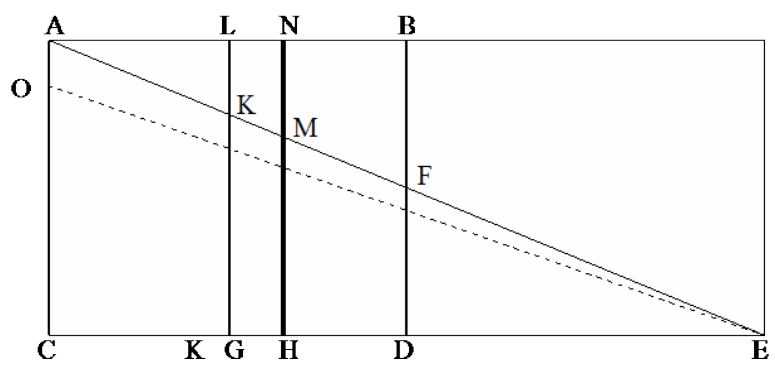

Figure 7. A variant of the helicon ${ }^{19}$.

\footnotetext{
${ }^{15}$ No reference is made at all to who those theoreticians were.

${ }^{16}$ Barker translates squares instead of rectangle: "they construct a square, ABCD" (Barker, 1989: p. 319). Indeed a little below Ptolemy said that $\mathrm{AB}=2 \mathrm{AE}$, and thus the rectangle is in fact a square.

${ }^{17}$ In the ratio $4: 3$.

${ }^{18}$ Redrawn from (Ptolemy, 2000: p. 67).

${ }^{19}$ Redrawn from (Ptolemy, 2000: p. 67).
} 
chords can be located and all sorts of ratios can be obtained.

\subsection{Extended Harmonics}

In the third book of the Harmonica Ptolemy enlarged the concept of harmonics, from music to psychology and astronomy. He reasserted the definition of harmonics, or better harmonic function. This was descrkibed as a function of reason that regards the symmetry of movements, a knowledge of which is expressed by mathematics, that studies the ratio of audible differences (Feke, 2009). This function of reason can be extended to any kind of regular motion:

It must be said in addition that it might be necessary for such a function to be present in all things which contain the beginning of motion, even to a small extent, just as the others," particularly and most extensively in those which share a more perfect and rational nature on account of the individual conditions of their creation. In these alone can it be shown universally and clearly to preserve as much as possible the similarity of those ratios which make what is suitable and harmonious in the different species.

For generally, whatever is governed by nature shares in reason to a certain extent both in motions and the basic subject matter. And where reason is able to be guarded with due proportion, here can be found creation, nurturing, preservation, and everything which is spoken of as superior (Ptolemy, 2000: p. 66).

I have omitted details on the parallel of harmonics in music and in the human soul and heavenly bodies. Only a list of the titles of the chapters of Book III which gives a clear idea of Ptolemy conceptions are provided.

1) How through the whole system we might both use and judge the ratios by means of the fifteen-stringed canon.

2) Methods for dividing up to the double diapason with only the eight notes.

3) In which genus must we place harmonic function and our knowledge of it?

4) That the function of the harmonic exists in the natures of all the more perfect things and that it appears particularly in both human souls and heavenly motions.

5) How the consonances are in accord with the first differences of the soul and their species.

6) A comparison between the harmonic genera and those of the first virtues.

7) How harmonic modulations resemble the circumstantial modulations of souls.

8) On the similarity of the perfect system and the circle through the middle of the zodiaco

9) How the harmonic consonances and dissonances resemble those in the zodiac.

10) That succession in notes resembles the longitudinal movement of the stars.

11) How the stellar movement in altitude compares with the harmonic genera.

12) That modulations of tonoi are like stellar crossings in latitude.

13) On the similarity of the tetrachords and the aspects of the sun.

14) By what first numbers might the fixed notes of the perfect system be compared to the first spheres in the cosmos.

15) How the ratios of their motions are calculated by the numbers.

16) How the combinations of the planets should be compared to those of the notes (Ptolemy, 2000: p. 127).

\section{Conclusion}

Harmonics had been an important mixed mathematics from Classical and Hellenistic Greece, throughout the Middle Ages and the Renaissance. Despite this, it has been largely ignored by historians of science. This paper shows that harmonics merits a careful study and that its methods are the same as other sciences, such as astronomy and mechanics, to name but a few. Harmonics, perhaps, was the only scientific discipline where experience was subject to real experiments, very similar to those carried out in modern laboratories.

Two different approaches to music are compared, which are also found in the other mixed mathematics. Aristoxenus and his school followed the approach of mixed mathematics as practiced by most mathematicians and theorized by Aristotle. The starting point was of an experimental nature and was considered as true, even though it was not framed in metaphysics where it could somehow also be regarded as evident. Experimental results served as a starting point for mathematical reasoning, for example, to demonstrate relationships among intervals. The use of mathematics by Aristoxenus could perhaps have been a legacy of his mathematical education and could have been ignored, focusing on demonstrations based on logical relationships only. However, Aristoxenus 
did not do this.

Ptolemy followed a different approach, typical of him. He proposed a number of hypotheses that were based on both empirical considerations and Pythagorean metaphysics. From these, he built a theory that he then submitted to experimental verification. Among his hypotheses was the fundamental hypothesis, according to which the pitches of notes could be attached to numbers and these numbers should combine according to appropriate ratios to obtain melodic sounds. Experimentation was carried out essentially with a system of vibrating strings (the monochord-canon, the octochord-canon, and the helicon) whose length can be adjusted. The tests were to be repeated many times in order to eliminate possible errors of observation. Probably the epistemological position of Ptolemy in his harmonic science was merely rhetorical and in fact expressed his general ideas on science. However, it may also be envisioned that he had deliberately undertaken a series of actual musical experiments. In any case, the Harmonica, probably a late work, provided him with the opportunity to clarify his ideas about science. It was not the scope of this paper to show if these ideas were received by modern scientists. I just say that this is probably true for Galileo (Drake, 1970; Drake, 1978; De Pace, 1993).

\section{References}

Aristoxenus (1902). The Harmonics of Aristoxenus. Edited and Translated into English by H. S. Macran Oxford: Clarendon Press.

Aristoxenus (1954). Aristoxeni Elementa harmonica. Edited and Translated into Italian by R. Da Rios. Rome: Publicae Officinae polygraphicae

Barbera, C. A. (1977). Arithmetic and Geometric Divisions of the Tetrachord. Journal of Music Theory, 21, $294-323$. http://dx.doi.org/10.2307/843492

Barker, A. (1978). Music and Perception: A Study in Aristoxenus. The Journal of Hellenic Studies, 98, 9-16. http://dx.doi.org/10.2307/630189

Barker, A. (1989). Greek Musical Writings (Vol. 2). Cambridge: Cambridge University Press.

Barker, A. (1994). Ptolemy's Phytagoreans, Architas, and Plato's Conception of Mathematics. Phronesis, 39, 113-135. http://dx.doi.org/10.1163/156852894321052135

Barker, A. (2006). Scientific Method in Ptolemy's Harmonics. Cambridge: Cambridge University Press.

Comotti, G. (1991). La musica nella cultura greca e romana. Turin: E.D.T.

De Pace, A. (1993). Le matematiche e il mondo. Milan: Francoangeli.

Drake, S. (1970). Renaissance Music and Experimental Science. Journal of the History of Ideas, 31, 483-500. http://dx.doi.org/10.2307/2708256

Drake, S. (1978). Ptolemy, Galileo, and Scientific Method. Studies in History and Philosophy of science, 9, 99-115. http://dx.doi.org/10.1016/0039-3681(78)90002-X

Düring, I. (1930). Die Harmonielehre des Klaudios Ptolemaios. Porphyrios Kommentar Zur Harmonielehre Des Ptolemaios. PhD Dissertation, Göthenburg: University of Göthenburg.

Düring, I. (1956) Greek Music: Its Fundamental Features and Its Significance. Journal of World History, 3, 302-329.

Feke, J. (2009). Ptolemy in Philosophical Context. Ph.D. Dissertation, Toronto: University of Toronto.

Laloy, L. (1904) Aristoxéne the Tarente et la musique de l'antiquité. Paris: Societé Français d'Imprimerie et de Libraire.

Litchfield, M. (1988). Aristoxenus and Empiricism: A Reevaluation Based on His Theories. Journal of Music Theory, 32, 51-73. http://dx.doi.org/10.2307/843385

Manolova, D. (2014). Discourse of Science and Philosophy in the Letters of Nikephoros Gregoras. Ph.D. Dissertation, Budapest: Central European University.

Palisca, C. V. (1961). Scientific Empiricism in Musical Thought. In: H. H. Rhys (Ed.), Seventeen Science and the Arts (pp. 91-137). Princeton, NJ: Princeton University Press.

Palisca, C. V. (1985). Humanism in Italian Renaissance. Musical Thought. New Haven, CT: Yale University Press.

Ptolemy, C. (2000). Ptolemy Harmonics. Translated and commented by J. Solomon. Leiden: Brill. 